\title{
The impact of phosphate scarcity on pharmaceutical protein production in S. cerevisiae: linking transcriptomic insights to phenotypic responses
}

\author{
Ali Kazemi Seresht ${ }^{1,2}$, Eva Akke Palmqvist ${ }^{1}$ and Lisbeth Olsson ${ }^{2 *}$
}

\begin{abstract}
Background: The adaptation of unicellular organisms like Saccharomyces cerevisiae to alternating nutrient availability is of great fundamental and applied interest, as understanding how eukaryotic cells respond to variations in their nutrient supply has implications spanning from physiological insights to biotechnological applications.
\end{abstract}

Results: The impact of a step-wise restricted supply of phosphate on the physiological state of $S$. cerevisiae cells producing human Insulin was studied. The focus was to determine the changes within the global gene expression of cells being cultured to an industrially relevant high cell density of $33 \mathrm{~g} / \mathrm{l}$ cell dry weight and under six distinct phosphate concentrations, ranging from $33 \mathrm{mM}$ (unlimited) to $2.6 \mathrm{mM}$ (limited). An increased flux through the secretory pathway, being induced by the PHO circuit during low $\mathrm{P}_{\mathrm{i}}$ supplementation, proved to enhance the secretory production of the heterologous protein. The re-distribution of the carbon flux from biomass formation towards increased glycerol production under low phosphate led to increased transcript levels of the insulin gene, which was under the regulation of the TPI1 promoter.

Conclusions: Our study underlines the dynamic character of adaptive responses of cells towards a change in their nutrient access. The gradual decrease of the phosphate supply resulted in a step-wise modulated phenotypic response, thereby alternating the specific productivity and the secretory flux. Our work emphasizes the importance of reduced phosphate supply for improved secretory production of heterologous proteins.

Keywords: Phosphate regulation, heterologous protein production, chemostat cultivations, human insulin, secretory flux, TPl1 promoter

\section{Background}

The long traditional attention and thus gathered familiarity with Saccharomyces cerevisiae is grounded on the deep knowledge about its genetics, physiology and cultivation techniques, making this eukaryote the main workhorse to study essential biological phenomena. Clearly, the gain of such immense knowledge fruited in many commercial success stories, when the formerly underrated baker's or brewer's yeast matured to one of

\footnotetext{
* Correspondence: lisbeth.olsson@chalmers.se

${ }^{2}$ Industrial Biotechnology, Department of Chemical and Biological

Engineering, Chalmers University of Technology, 41296-Gothenburg, Sweden Full list of author information is available at the end of the article
}

the most widely used hosts for a large portfolio of products derived by means of recombinant DNA technology. Regarding its revenue and market, the production of active pharmaceutical ingredients (APIs) represents currently with annual global sales of approx. US\$ 100 billion (reviewed by [1]), a significant field of research for improved yeast cell factory design.

The biotechnological production of human Insulin in S. cerevisiae (comprehensively reviewed by [2]) is considered to be the first of such successful commercial achievements, and represents even today, due to its enormous medical and market value, a highly important field of research. Despite the recent developments

\section{() Biomed Central}

(c) 2011 Seresht et al; licensee BioMed Central Ltd. This is an Open Access article distributed under the terms of the Creative Commons Attribution License (http://creativecommons.org/licenses/by/2.0), which permits unrestricted use, distribution, and reproduction in any medium, provided the original work is properly cited. 
within the field of metabolic engineering and synthetic biology, which mostly target the production of metabolites like organic acids [3] and the reinforced alternatives to former petrochemical-based compounds (reviewed by [4] and [5]), only little novel engineering has been achieved in yeast with respect to its secretory abilities. Strain engineering approaches towards enhanced secretory production of APIs remain essentially on the levels of target gene amplification, over-expression of few ERassociated foldases [6], and the engineering of modified secretion signals that supposedly aim at optimizing the trafficking and release of the heterologous package (reviewed by [7]). The secretory machinery of eukaryotes like $S$. cerevisiae, embodying its severe quality control abilities and the performance of complex posttranslational modifications, is still providing a partly undiscovered and thus fruitful ground for biotechnological progress with respect to both quantitatively and qualitatively enhanced production of APIs. In particular, the popular metabolic engineering philosophy of channeling an increased flux towards a given metabolic pathway turns out to be more challenging when it comes to increasing the secretory flux of the cells, as engineering of yeast protein factories still remains on the level of chaperone and ER resident folding catalysts (reviewed by [8])

One of the key elements for optimized production of APIs has traditionally been the design and deployment of growth media in which the cells are provided with excess nutrients to grow, multiply, and to produce the protein of interest. Such nutritious media support first of all the growth of the recombinant cells, compensating the additional burden derived from the over-production of the heterologous protein. But, could the excess supply of nutrients potentially saturate, and thus partly silence, biosynthetic and reshuffling processes of key API precursors? And would these processes, when stimulated under nutrient hunger, improve the processing, e.g. maturation and secretion of the protein of interest?

Growth under nutrient limited conditions has been investigated in many cases during the past, facilitating advanced physiological characterization of the cells. We learned that by throttling the evolutionary favored biomass formation, the salvaged energy and metabolic precursors can be re-distributed towards a particular biosynthetic process, leading to the development of novel bioprocessing strategies based on limited nutrient supply, e.g. fed batch and continuous cultivations. As a matter of fact, the yeast S. cerevisiae has great capabilities of responding to alternations in its nutrient availability. As a unicellular system, it has evolutionary matured measures to quickly respond to any changes in its environment, and it does so through re-distribution of energy and biosynthetic fluxes.
Inorganic phosphate $\left(\mathrm{P}_{\mathrm{i}}\right)$ is an essential nutrient for any organism, as it is required for the biosynthesis of nucleotides, phospholipids and metabolites, in energy metabolism, and it acts as an important messenger in signal transduction processes. Sophisticated and efficient regulatory circuits are needed for proper management of mechanisms like acquisition, storage, and utilization of phosphate. Recent studies have examined the impact of limiting nutrient availability, e.g. C-, N-, P-, and Slimitation, on a global scale of endo-metabolome [9], proteome [10], transcriptome [11], or in combination [12], to name a few. These studies (and references herein) revealed close interconnection among the global transcriptome and the specific growth rate, and further highlighted the major physiological impact of carbon limitation compared to the limitation of other nutrients, e.g. nitrogen, phosphor and sulfur.

Yet, we suspect that the adaptive response of cells towards a change in their nutrient access is a dynamic process, meaning that cellular regulatory events do not necessarily happen at the point of any particular limitation, but follow a more transient progression from one physiological bottleneck to the other. The understanding of such regulatory events necessitates, besides to the perception of physiological changes at limiting levels of a given nutrient, also the observation of the progressive changes during a step-wise reduced supply of that particular nutrient. In this study, we followed the transcriptional impact of a step-wise reduced supply of phosphate to cells that were growing under carbon limited condition in chemostat cultivations. As all our investigated $S$. cerevisiae cultures were growing with essentially the same fixed specific growth rate, i.e. being fed by a controlled and limited supply of carbon, any cellular response being not related to the alternating phosphate supply was out-normalized. Besides, we put, to our knowledge for the first time, the impact of a variable phosphate supply in a context of the production of a heterologous protein, in our case a human Insulin Analogue Precursor (IAP), in S. cerevisiae. Yet another novelty of our work is the fact that we examined the cells in a more industrially relevant context than it is generally done in nutrient limitation studies. The cultivations of the cells were performed at high cell density in sophisticated continuous chemostat cultivations and the analysis were carried out under steady state conditions, increasing the quality of the obtained biological insights. The S. cerevisiae cultures in this study grew at 10 fold higher glucose levels in the feed supply as compared to standard laboratory practice, resulting in reduced $\mathrm{P} / \mathrm{C}$ ratios (phosphate to glucose ratio) and thus lower residual phosphate levels.

To address the impact of low $\mathrm{P}_{\mathrm{i}}$ on the physiological state of $S$. cerevisiae in a more progressive manner, we 
carried out individual cultivations at six distinct phosphate supplies, chosen to cover the range from excess to limiting levels. We monitored general physiological changes, in terms of biomass formation, major exometabolite secretion, and insulin production, in relation to a diminishing phosphate supply. We followed the global transcriptome as a function of supplied $P_{i}$ in two complementary ways: in a rigid way, based on a differential expression analysis (DEA) approach among cultures growing under high versus low $\mathrm{P}_{\mathrm{i}}$ conditions, and in a consecutive way, based on a significant profile analysis (SPA) approach following the progression of transcriptional changes from carbon limited to phosphate limited growth. Our data contribute to the fundamental understanding of cellular responses that are induced when $S$. cerevisiae cells sense a diminishing phosphate supply. In addition, we emphasize the importance of both the design of growth media with reduced phosphate levels and the choice of promoter for the expression of the recombinant gene, resulting in improved production of the heterologous protein of choice.

\section{Results}

Initially, we investigated the impact of a reduced phosphate supply on the metabolism and, more importantly, on the IAP productivity. The aim was to identify a physiologically feasible range of the supplied phosphate $\left(\mathrm{P}_{\mathrm{i}}\right)$ level. Based on the outcomes, a range of interest was identified, and a comprehensive study on the global impact of sequentially decreasing $P_{i}$ was designed. For identifying the impact of reduced $\mathrm{P}_{\mathrm{i}}$ supply on IAP production, we chose to gradually wash-out the $P_{i}$ from the initial medium whilst maintaining the specific growth rate of the cells, using a fixed dilution rate in the chemostat set-up. The gradual decrease of the feed supply rate (pump 1) was compensated by a gradual increase of the feed rate of a medium lacking any phosphate source (pump 2), thereby maintaining the overall feed rate constant and equal to the effluent flow (Figure 1A). The $\mathrm{P}_{\mathrm{i}}$ wash-out was initialized after keeping the culture for a minimum of five volume exchanges at steady state conditions. The estimated $\mathrm{P}_{\mathrm{i}}$ levels in the culture were calculated, neglecting possible delays due to mixing time, as a relatively high stirrer speed was chosen (1000 rpm). Before reaching the point of cell wash-out (absolute $\mathrm{P}_{\mathrm{i}}$ limitation) in the later stage of the process (after $200 \mathrm{~h}$ of cultivation, data not shown), a clear impact of the reduced $\mathrm{P}_{\mathrm{i}}$ supply to the IAP production and biomass formation was found (Figure 1B). An enhanced IAP production was observed at reduced $\mathrm{P}_{\mathrm{i}}$ levels, although the overall metabolism, displayed by the $\mathrm{CO}_{2}$ profile, seemed to be only slightly affected.

\section{Physiological characterization of the cells with respect to the impact of $P_{i}$ supply}

To understand the cause of increased IAP production on a more ample perspective, we ran six separate chemostat cultivations, supplying six distinct $\mathrm{P}_{\mathrm{i}}$ concentrations $33 \mathrm{mM}, 22 \mathrm{mM}, 14.7 \mathrm{mM}, 9.6 \mathrm{mM}, 5.5 \mathrm{mM}$, and $2.6 \mathrm{mM}$, respectively, thus covering the determined range of interest derived from our initial experiment. All six cultivations were analyzed for general exo-metabolites, i.e. residual glucose, ethanol, glycerol and acetate, as well as for the secreted amount of the target protein (IAP), biomass (via $\mathrm{OD}_{600}$ and cell dry weight analysis), and global gene expression levels (on oligonucleotide microarrays). The respiratory activity of the cells (based on the carbon dioxide production level) was monitored on-line and used for steady state determination. Once the cultures fulfilled and maintained steady state conditions for 10 generations, a sampling regime of two samples per day was followed for 4-5 days. The resulting samples were analyzed as described, and the corresponding yields on biomass (production yields, $\mathrm{y}_{\mathrm{i} / \mathrm{X}}$ ) and glucose (consumption yields, $\mathrm{Y}_{\mathrm{i} / \mathrm{S}}$ ) were determined (Figure $1 C)$.

A first glance on the physiological observations pictured major changes in the metabolism and IAP expression within the chosen range of phosphate supply. The biomass formation yield $\left(\mathrm{y}_{\mathrm{X} / \mathrm{S}}\right.$ ) did not show any significant changes within the $\mathrm{P}_{\mathrm{i}}$ range of $33 \mathrm{mM}(0.424 \pm$ $0.008 \mathrm{~g} / \mathrm{g})$ to $14.7 \mathrm{mM}(0.421 \pm 0.004 \mathrm{~g} / \mathrm{g})$. Also, no significant changes in the glycerol and ethanol yields were detected in this range (changes within the standard deviation). Yet, a first increase of the IAP production yield $\left(\mathrm{y}_{\mathrm{P} / \mathrm{X}}\right)$ was noticeable, increasing 22.6\%, from 1.93 $\pm 0.08 \mathrm{mg} / \mathrm{g}(33 \mathrm{mM} \mathrm{P}$ i $)$ to $2.37 \pm 0.04 \mathrm{mg} / \mathrm{g}(14.7 \mathrm{mM}$ $\mathrm{P}_{\mathrm{i}}$ ). When the supplied $\mathrm{P}_{\mathrm{i}}$ level was further decreased to 9.6 mM, major metabolic shifts were observed, leading to a re-distribution of the carbon flow from biomass formation $\left(\mathrm{Y}_{\mathrm{X} / \mathrm{S}}\right.$ decreased about $14.6 \%$ to $0.362 \pm 0.004 \mathrm{~g} /$ g glucose) towards both glycerol formation $\left(\mathrm{Y}_{\mathrm{G} / \mathrm{S}}=\right.$ $0.615 \pm 0.041 \mathrm{mM} / \mathrm{M}$ glucose) and ethanol formation $\left(\mathrm{Y}_{\mathrm{E} / \mathrm{S}}=0.287 \pm 0.031 \mathrm{mM} / \mathrm{M}\right.$ glucose $)$, indicating a shift from an initially respiratory to an appearing respiro-fermentative metabolism. The IAP production yield further increased to $\mathrm{y}_{\mathrm{P} / \mathrm{X}}=2.98 \pm 0.09 \mathrm{mg} / \mathrm{g}$ and was thus $54 \%$ higher than the initial yield at $33 \mathrm{mM} \mathrm{P}_{\mathrm{i}}$. The further decrease of the $\mathrm{P}_{\mathrm{i}}$ supply led to a major loss of biomass yield, due to augmented by-product formation (Figure 1D). A new range of interest with respect to the following transcriptome analysis was chosen, thus being further narrowed down to the range of $22 \mathrm{mM}$ to 9.6 $\mathrm{mM}$ phosphate supply, as this range showed an interesting increase of IAP productivity without significant loss of carbon flux towards by-product formation. 


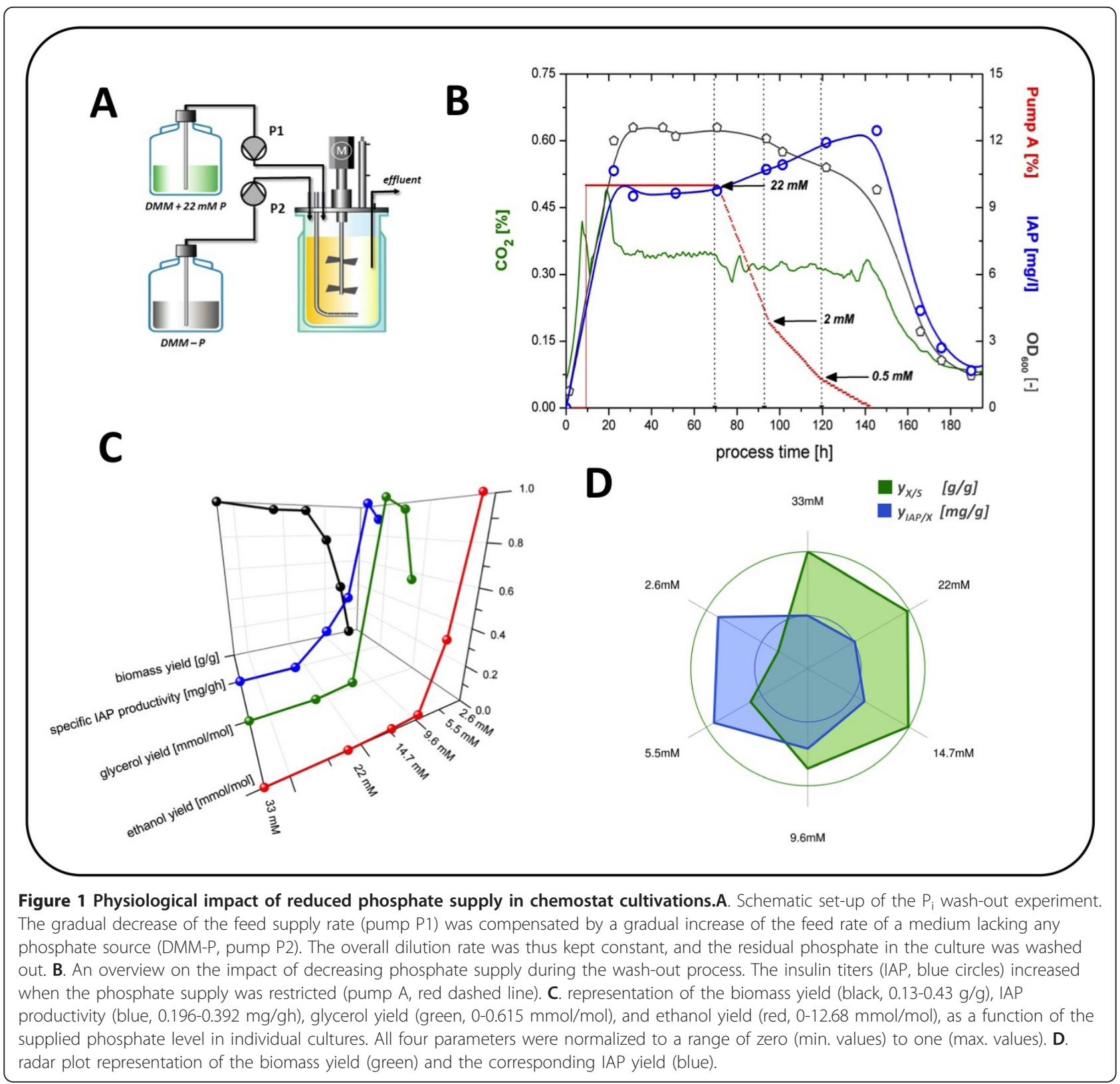

Transcriptome analysis I: Differential Expression Analysis (DEA) of [22 $\mathrm{mM} \mathrm{P}_{\mathrm{i}}$ ] vs. [9.6 $\mathrm{mM} \mathrm{P}_{\mathrm{i}}$ ]

We carried out a pair-wise comparison between the cultures grown at $22 \mathrm{mM}$ and $9.6 \mathrm{mM}$ phosphate for exploring the global transcriptional impact on cells under low and high phosphate levels, respectively. We identified 381 genes being significantly differentially expressed (statistical significance, Benjamini \& Hochberg FDR adjusted $p \leq 0.05$ ) in a comparison of cultures supplied with $9.6 \mathrm{mM}$ phosphate $[9.6 \mathrm{mM}$ ] to the control culture, being supplied with $22 \mathrm{mM}$ phosphate [22 $\mathrm{mM}$. The majority of these genes (217) were up-regulated in $[9.6 \mathrm{mM}]$. A second significance trap (biological significance) was set to further narrow down the genes of interest, choosing a fold change cut-off of abs(FC) $\geq$ 2 , resulting in a decrease of significant differentially expressed genes to 146 genes, of which 87 were upregulated in $[9.6 \mathrm{mM}]$. Within the top ten genes being up-regulated, we identified five phosphatases $\mathrm{PHO} 3$ (15.1-fold), PHM6 and PHM8 (17.6-fold and 9.4-fold), PHO11 (6.5-fold), and HOR2 (4.6-fold), besides to the permease GIT1 (17.8-fold) being highly expressed under low $\mathrm{P}_{\mathrm{i}}$ conditions. AGene Ontology (GO Slim) enrichment analysis was performed and enriched categories (Figure 2), which together represented the majority of the identified genes being either up- or down-regulated, 


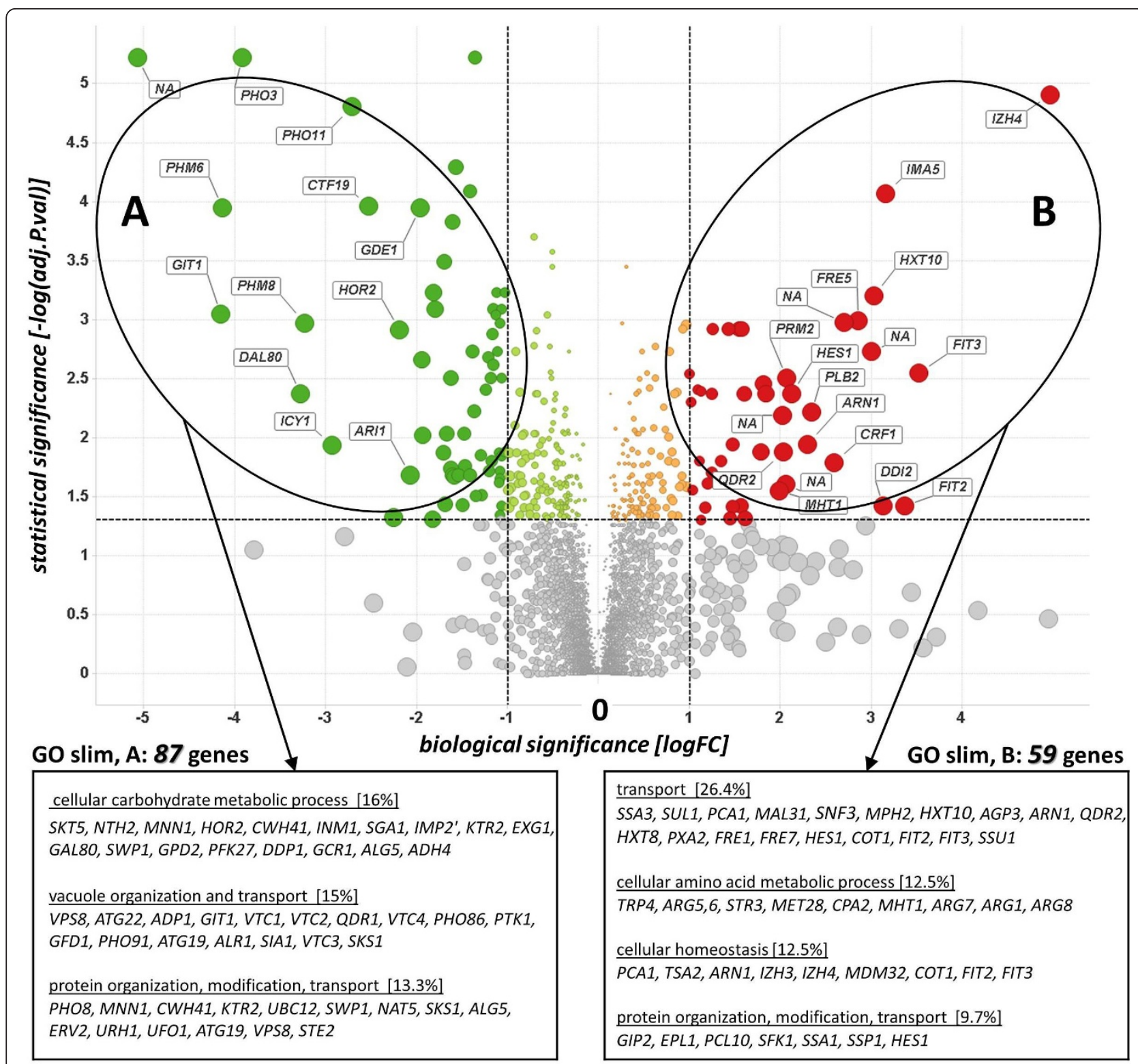

Figure $2 \mathrm{~A}$ volcano plot representation of the differentially expressed genes in a pair-wise comparison of cultures growing at high phosphate level $[22 \mathrm{mM}]$ to low phosphate level $[9.6 \mathrm{mM}]$. The significance cut-off was set to a FDR of 0.05 (-log(adj.P.val $\geq 1.3)$, the biological cut-off was set to a fold change of \pm 2 fold $(-1 \geq \operatorname{logFC} \geq 1)$, the top 30 differentially expressed genes are labeled with their corresponding gene ID, the absolute fold change of all genes are represented by the circle size, the five different color codes used represent insignificant genes (grey), both biologically and statistically significant genes being up-regulated (red, B) and down-regulated (green, A) at [22 $\mathrm{mM}] \mathrm{P}_{\mathrm{i}}$, statistically but not biologically significant genes being up-regulated (orange) and down-regulated (light green) at [22 $\left.\mathrm{mM}\right] \mathrm{P}_{\mathrm{i}}$, respectively. A GO slim enrichment analysis of the gene sets A and B revealed the over-representation of the pictured $\mathrm{GO}$ terms within the gene sets $A$ and $B(\%)$, the group of genes with an unknown biological function for gene set A (26\%) and gene set B (25\%) was excluded from further analysis.

were identified. The enriched categories related to vacuole re-organization and protein maturation and transport were considered to be very interesting, as the secretory production of the heterologous IAP was expected to be positively affected by the up-regulation of the genes involved in the secretory machinery and the recycling compartment of the cells, presumably leading to an increased protein processing capacity of the cells. The third enriched category of carbohydrate metabolism revealed a first indication that a cross-talk between phosphate supply and glycolytic flux does exist. As the recombinant insulin gene cassette was put under the regulation of the constitutive TPI1 promoter, we assumed another, possibly positive, effect of low $P_{i}$ 
supply to IAP expression due to the choice of a glycolytic promoter.

One drawback of such a stringent Differential Expression Analysis (DEA) approach is the risk of losing potentially valuable information on co-regulated genes and their inter-connection among distinct pathways. By using statistical and biological cut-offs for separating the wheat from the chaff in a biological sense, only pieces of a big regulatory picture are revealed, mostly due to the fact that different steps in a given metabolic pathway can be more or less transcriptionally regulated, depending on the complexity of the encoding enzymes. As shown in (Figure 2), the sixth part in the lower right part of the plot-representing genes which are highly upregulated in the high $P_{i}$ supplied culture $[22 \mathrm{mM}]$, yet which failed to pass the chosen statistical trap-encloses significantly more genes as compared to the top right sixth part. Also, the chosen biological cut-off led to a non-observance of $65 \%$ of the statistically significant genes (top middle sixth part), which potentially would contribute to a more sophisticated biological mining of the observed physiological state of the cells. This possible drawback was counteracted in a second approach, where the focus was set to genes with a significant expression profile as a function of supplied phosphate.

\section{Additional insights to transcriptional changes via the Significant Profile Analysis (SPA) approach}

Our intention then was to salvage more in depth insights into the impact of the altered phosphate supply and its relation to insulin production. We suspected that, by considering the expression pattern of any significant gene, and by identifying gene clusters which show a progressive trend as a function of the change in their phosphate availability, more in depth biological insights regarding regulatory events can be found. For this, we used a regression based methodology which is in more common practice in time course experiments [13]. By substituting the time factor with our compiled range of interest for $\mathrm{P}_{\mathrm{i}}$ concentration, the examined phosphate levels were taken into account in a progressive manner. However, we did not include data of the culture which was supplied with the lowest $\mathrm{P}_{\mathrm{i}}$ level $[2.6 \mathrm{mM}]$, as we considered the physiological changes that occurred at this level to be too abundant and not in favor of the production of our target protein. Using the MicroArray Significant Profiles (maSigPro) tool, 1289 genes were identified which pictured a significant alternating expression profile as a function of the supplied phosphate amount. These profiles were then separated in an array of nine clusters and further sieved for similarity with the more macroscopic determined trend of $\mathrm{y}_{\mathrm{P} / \mathrm{X}}$ (Figure 3A). We identified each two clusters of genes with increasing (cB1 and $\mathrm{CB} 2$ ) and two clusters with decreasing (cA1 and cA2) trend as a response to decreasing $P_{i}$ supply.

The clusters cA1 and cA2 showed a general similarity, and more interestingly, no significant change in the expression for the range of $33 \mathrm{mM}$ to $14.7 \mathrm{mM} \mathrm{P} \mathrm{P}_{\mathrm{i}}$, reflecting our previous observations with respect to the general physiological state of the cells within this range. As compared to the DEA results, and taking into account the quantity of genes found in cA1 (283 genes) and cA2 (202 genes) picturing a significant profile, additional information on down-regulated biological processes were found with respect to a decreasing phosphate supply. The clusters cB1 (115 genes) and cB2 (78 genes) constitute genes which showed an increasing expression profile as a response of decreasing $P_{i}$ supply. Again, cluster $\mathrm{cB} 1$ shows an interestingly high similarity to our physiological data, as it represents genes with increased transcript levels when the phosphate concentration is reduced to $9.6 \mathrm{mM}$ and below. In contrast, the genes encompassed within cluster cB2 pictured a more sensitive response to the reduction of phosphate in the corresponding cultures, as their expression changes throughout the entire range of examined $P_{i}$ supply. All four clusters where then surveyed for enriched GO Slim categories, (Figure 3C.1 and 3C.2), representing the majority $(>65 \%)$ of the comprising genes of the individual clusters. Besides to the significantly enriched group of gene with unknown biological process $(>20 \%)$ which was excluded from the data mining, we identified GOs related to protein maturation and transport being enriched in all clusters, representing approx. half of all clustered genes (see also additional file 1). As both increasing and decreasing expression profiles showed enriched GOs in these terms, we regarded these outcomes as a clear indication of a changing flux through the cell-internal secretory pathway, and with respect to the observed boost of the secretory production of the heterologous protein IAP, as highly valuable. Interestingly, the cluster of genes with the most sensitive response towards the variation of the $P_{i}$ supply (cB2) was also enriched in the GO categories related to carbohydrate metabolism. Considering the transcriptional regulation of the insulin gene, which is under the regulation of the glycolytic TPI1 promoter, this finding implies a possible increase of the IAP transcript levels to be a cause for its increased production under reduced phosphate conditions.

In this study, additive information on transcriptional changes was obtained when two different methodologies were applied. Considering the consecutive expression pattern of genes over the full range of the examined phosphate levels proved to enrich the data derived from a transient analysis of the transcriptional changes among low $(<9.6 \mathrm{mM})$ versus high $(>22 \mathrm{mM}) \mathrm{P}_{\mathrm{i}}$ levels. As shown in (Figure 4A), both the pair-wise comparison (DEA approach) and the regression based profile 


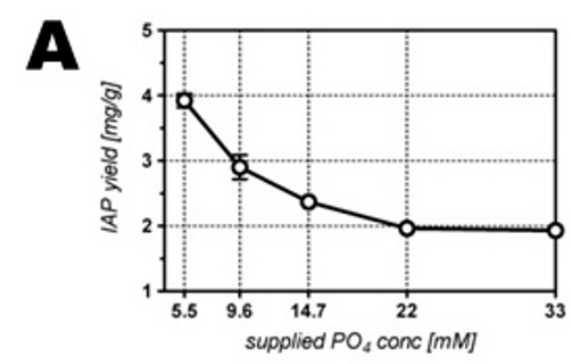

\section{C.1}
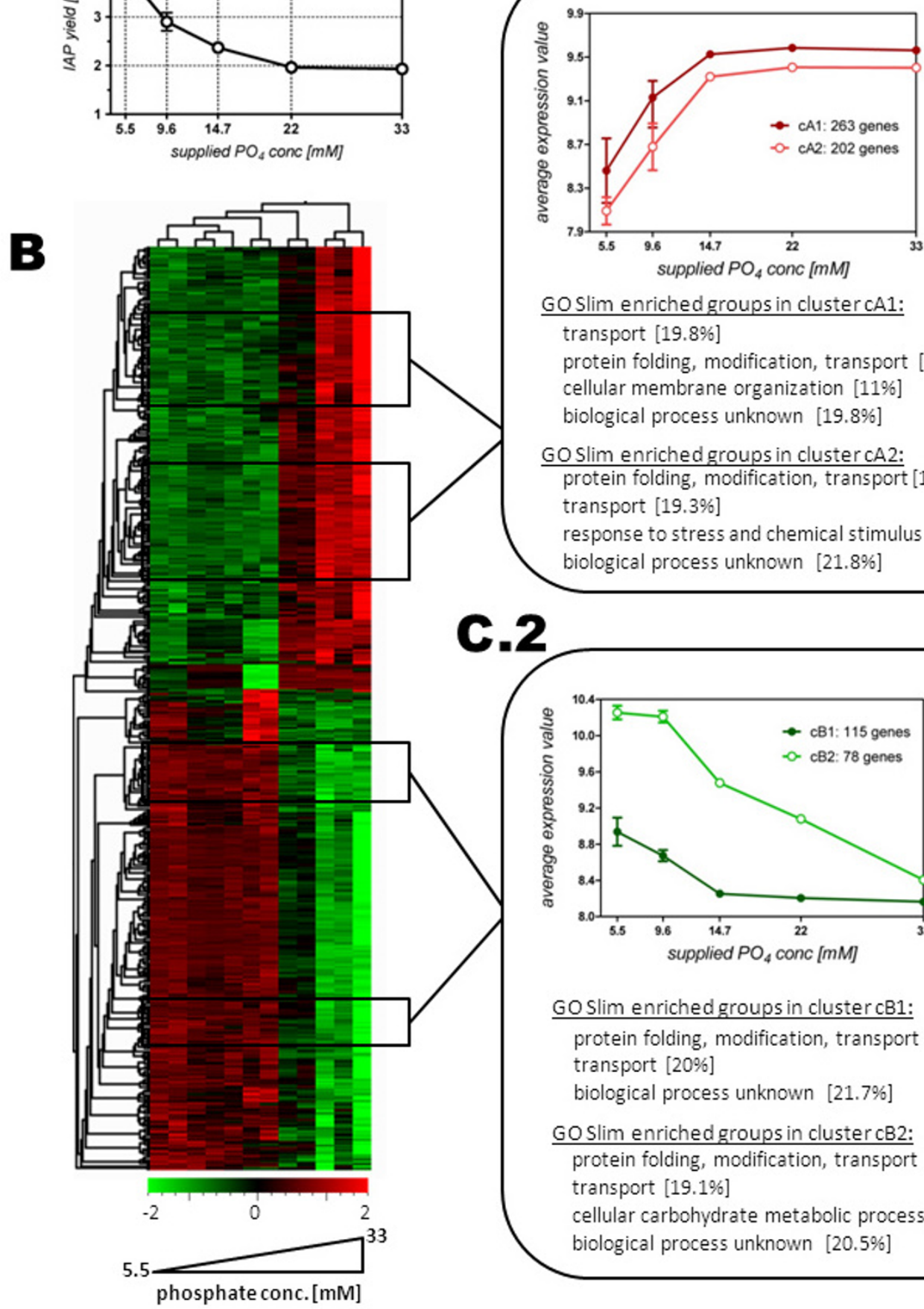

GOSlim enriched groups in cluster CA1:

transport [19.8\%]

protein folding, modification, transport [15.6\%]

cellular membrane organization [11\%]

biological process unknown [19.8\%]

GOSlim enriched groups in cluster CA2:

protein folding, modification, transport [19.8\%]

transport [19.3\%]

response to stress and chemical stimulus [13.4\%]

biological process unknown [21.8\%]

\section{2}

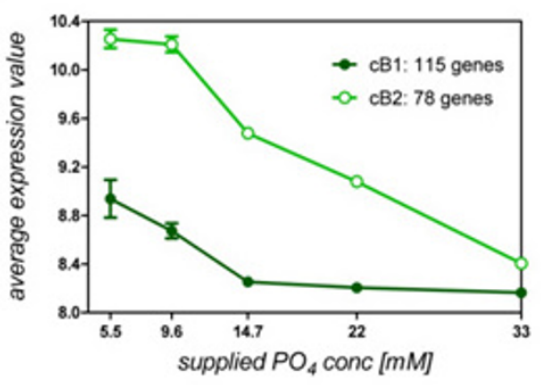

GOSlim enriched groups in cluster cB1:

protein folding, modification, transport [23.5\%]

transport [20\%]

biological process unknown [21.7\%]

GOSlim enriched groups in cluster cB2:

protein folding, modification, transport [19.2\%] transport $[19.1 \%]$

cellular carbohydrate metabolic process $[15.4 \%]$

biological process unknown [20.5\%]

Figure 3 Identification of significant gene expression profiles in relation to the observed IAP expression dynamics. A. The insulin yield on biomass, as a function of supplied phosphate. B. a heat map of the hierarchical clustering analysis based on genes picturing a significant expression profile as a function of supplied phosphate; the lowest examined phosphate level [2.6 mM] was excluded from the SPA analysis; the color code represents the scaled expression values. C.1. Two clusters CA1 (263 genes) and CA2 (202 genes) were selected, harboring genes with declining expression profile with diminishing phosphate levels. The GO slim enrichment analysis identified each four categories, covering $66 \%$ (CA1) and 74\% (CA2) of genes within each cluster.C.2. Two clusters CB1 (115 genes) and CB2 (78 genes) were selected, harboring genes that showed, similarly to the IAP yield, an increasing expression profile with decreasing phosphate levels. The GO slim enrichment analysis identified three (CB1) and four (CB2) enriched categories, covering 65\% (CB1) and 74\% (CB2) of gene within each cluster, respectively. 


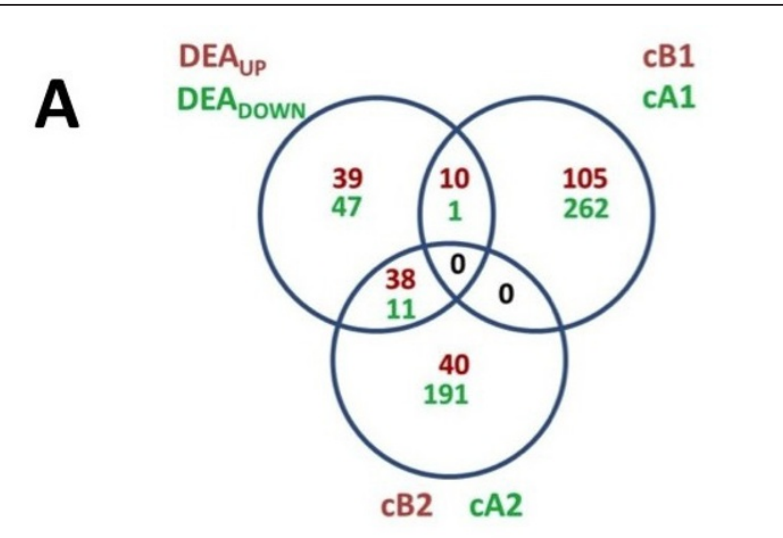

B
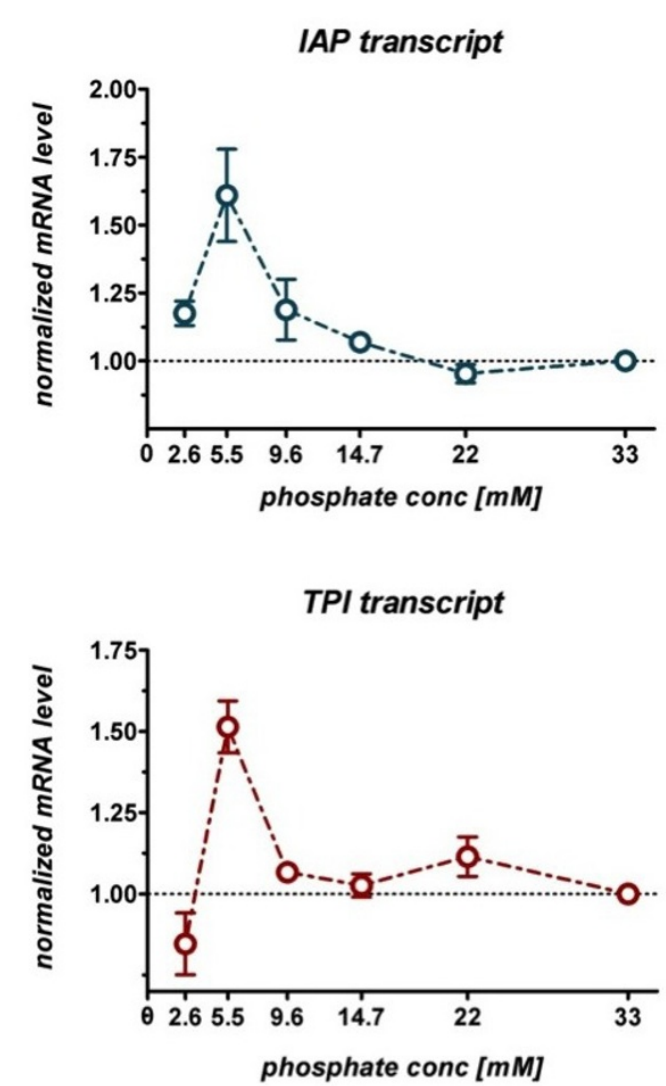

Figure 4 Mining the impact of phosphate scarcity by using complementary gene expression data sets. A. Venn diagram representing the overlapping genes identified with the DEA approach (comparison of cultures growing at low and high phosphate levels) and the SPA approach (consecutive analysis of gene expression patterns as a function of phosphate supply; gene numbers with increasing expression at low phosphate (dark red) and gene with decreasing expression at low phosphate (green) are highlighted. B. RT-PCR analysis of the transcript levels of insulin gene (blue) and the TPI1 gene (red) as a function of supplied phosphate; increased levels of the IAP transcript were measured under low phosphate levels; the mRNA levels are normalized to their initial quantities at high phosphate levels [33 mM]; cultures grown under limited phosphate supply $[2.6 \mathrm{mM}]$ showed decreased IAP and TPI1 transcript levels. analysis (SPA approach) led to a complementary amount of significant genes which supported the process of biological mining of the observed phenomena. Both, the overlaps between down-regulated genes in the DEA approach and the SPA derived clusters cA1 (1) and cA2 (11), and the up-regulated genes among the DEA approach and the clusters cB1 (10) and cB2 (38), respectively, represent the complementation of both methodologies.

\section{The impact of reduced phosphate supply on the transcription of the insulin gene}

For investigating the directed impact of the reduced $\mathrm{P}_{\mathrm{i}}$ supply to the target gene expression, we performed RTPCR experiments on both the transcripts of the insulin gene (IAP) and for the TPI1 gene (TPI), as the regulation of TPI1 was expected to have an impact on the expression levels of insulin (same promoter). As suggested by the gene ontology enrichment analysis, an increased glycolytic activity was observed when cultures were grown under low phosphate conditions [below $14.7 \mathrm{mM}$ ]. Although we identified relatively distinct parts of carbohydrate metabolism to be differentially regulated, i.e. glycerol biosynthesis (GPD2, HOR2) and the down-stream part of glucose fermentation ( $P Y K 2$, PDC6, ADH1,4), we predicted the central node of these two pathway branches within the glycolysis, encoded by TPI1, to be affected in accordance.

The obtained transcript levels of the IAP and TPI1 were normalized to the levels found under high (33 $\mathrm{mM}$ ) phosphate levels (Figure 4B). Both genes showed a similar profile and significantly increased levels under low $\mathrm{P}_{\mathrm{i}}$. In addition to our first conjecture that the increased flux through the secretory pathways of the cells benefits the heterologous insulin production, we concluded that the elevated insulin production yields observed under low phosphate are also enrooted on its increased transcript levels.

\section{Discussion}

Under phosphate limiting conditions, the phosphate signal transduction $(\mathrm{PHO})$ pathway is activated, leading to a coordinated cellular response through a transcriptional induction of a wide regulatory circuit, involving genes coding for a high affinity transport system (PHO84, PHO89), acid phosphatases (PHO5, PHO11, PHO12), alkaline phosphatase (PHO8), polyphosphate storage (PHM1 to PHM5), and genes involved in the catabolism of alternative phosphorous sources (GIT1, GDE1, HOR2) [14-16]. The actual activation of the $P H O$ pathway is triggered by the inhibition of the cyclin-dependent kinase (CDK) complex Pho80-Pho85 via the CDKinhibitor Pho81 [17]. Very recently, it has been shown that a small molecule ligand, inositol heptakisphosphate 
$\left(\mathrm{IP}_{7}\right)$, is required for inducing the inhibitory activation of Pho81 on the CDK complex [18], thereby preventing that the kinase complex would hyperphosphorylate the transcription factor Pho4. The unphosphorylated Pho4 can then associate with the nuclear importer receptor Pse1 and translocate into the nucleus, and in cooperation with another transcription factor Pho2, activate the PHO-responsive genes [19].

Our data show a significant up-regulation of all named high affinity phosphate transporters and acid phosphatases but one, being PHO5 (Figure 5, top right). It has been shown that enzymes involved in inositol pyrophosphate synthesis appear to be essential for the regulation of PHO5 expression [20]. In fact, KCS1, which has been shown to suppress PHO5 expression under low phosphate conditions, is in this study more than three fold up-regulated. Together with the two up-regulated genes INM1 and PIS1 which are both encoding enzymes further upstream in the inositol phosphate pathway, we have an indication for the cross-talk of inositol pyrophosphate formation and $\mathrm{PHO}$ pathway activation. Evidence of the cross-talk has also been found by [21], who reported the cellular component stimulating the Pho81dependent inhibition of the CDK complex to be the product of both $\mathrm{IP}_{6}$ kinases Kcs1 and Vip1. The implications of the non-differentially expression of $\mathrm{PHO5}$ under reduced phosphate concentrations for the design of improved expression systems is significant. The PHO5 promoter has been a preferred regulator of heterologous protein production, as cells which have been grown under phosphate limitation over-express this acid phosphatase gene and consequently the heterologous protein that has been put under the inducible $\mathrm{PHO5}$ promoter $[22,23]$. Our data underlines the benefit of using the non-inducible TPI1 promoter, as the expression of the target protein was positively affected by the reduction of the phosphate level in the media through-out the examined phosphate range, whereas the a PHO5-dependent expression would most likely show a benefit only at limiting but not reduced phosphate levels.

Interestingly, when the phosphate concentration in the medium is decreased, polyphosphate accumulation in the vacuoles mediated by the vacuole transporter chaperone (VTC) complex, of which the four sub-units are

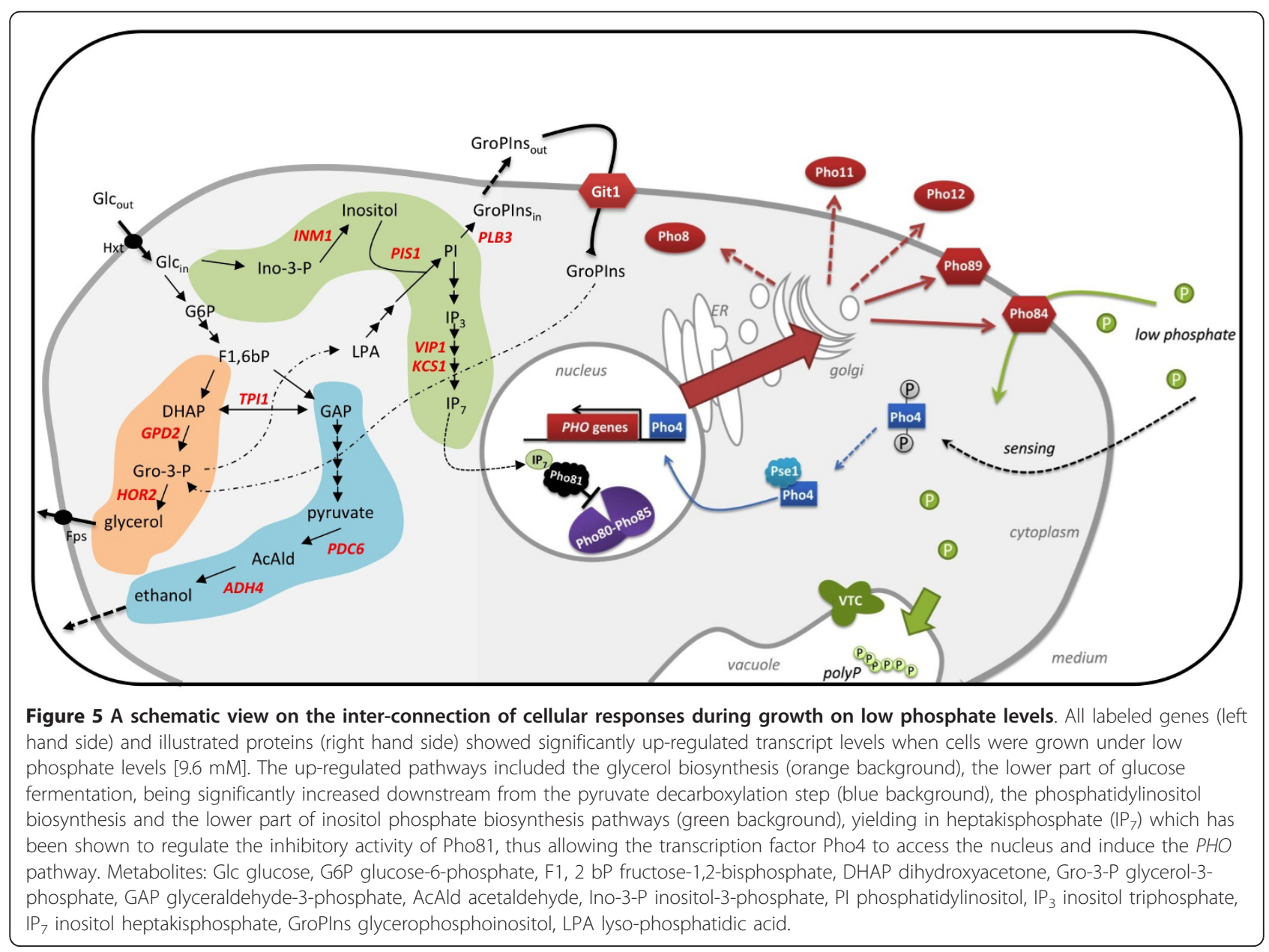


encoded by PHM1 to PHM4 (alias VTC1-4), was 2-3 fold up-regulated (Figure 5, lower right). Although this seems to be contradictory, as polyphosphates represent a $P_{i}$ reserve used during periods of $P_{i}$ starvation [24], the increased intracellular phosphate levels, mostly obtained by the high-affinity phosphate uptake mediated by Pho84, need to be stored as polyphosphates in the vacuoles for avoiding possible negative feedbacks to the uptake system. As reported by Ogawa and co-workers [16], increased cell-internal $P_{i}$ levels would lead to inhibitory effects on Pho84, thus counter-acting the highaffinity transport system.

Our data show that the inositol biosynthesis pathway is partly up-regulated with decreasing phosphate concentration in the medium. As the inositol concentration in the media was kept constant for all investigated media formulations, and INO1, encoding the first and rate-limiting enzyme in inositol biosynthesis, did not show any significant differential expression, no indication of inositol limitation were found. Still, with the upregulation of INM1 and PIS1, we had indications that the formation of phosphatidylinositol (PI) was increased (Figure 5, green cloud). Being an essential lipid for eukaryotic cells, PI acts as a precursor for sphingolipids, polyphosphoinositides, and most interestingly for glycerophosphoinositol (GroPIns). The latter is derived trough deacylation via phospholipases like PLB2, which in turn was also up-regulated. It has been shown that GroPIns, as a major PI catabolite in inositol containing medium, is released to the extra-cellular milieu [25]. Under both phosphate and inositol limiting conditions, GroPIns can be transported into the cells, mediated by a permease encoded by the GIT1 gene [26]. This permease gene was found to be more than 17 fold increased and among the top five genes we identified in this study to be significantly differentially expressed in the pair-wise comparison of high vs. low $\mathrm{P}_{\mathrm{i}}$. Our data underline the outcomes of [27] who have reported an accumulation of GIT1 transcripts when phosphate limitation is artificially imposed in a $\Delta p h o 85$ strain. The findings are also in accordance with Almaguer et al. [28] who also have reported that GIT1 transcript levels and Git1p activity are higher in cells starved for phosphate with or without inositol limitation. The latter study also concludes that GroPIns can act as the sole phosphate source for cells.

Both the physiological and the transcriptional changes observed in this study suggest a carbon flux re-distribution within the glycolysis towards increased glycerol formation. The increased transcript levels of GPD2, a NAD-dependent glycerol-3-P dehydrogenase, and HOR2, a glycerol-3-P phosphatase, (Figure 5, orange cloud) lead to a more than 30 fold increase of the extracellular glycerol (Figure 1C). Interestingly, GPD2 and HOR2 are known to be induced under anaerobic conditions and hyperosmotic stress, respectively [29], yet these are not the conditions of our study. However, it has been reported that the GPD2 transcript levels respond to fluctuations of the cytosolic NADH/NAD ${ }^{+}$ ratio and thus to the redox state of the cytosol [30]. In a recent study committed by Lu et al. [31], it has been shown that components of the $P H O$ pathway play important roles in $\mathrm{NAD}^{+}$metabolism. It has been reported that low $\mathrm{P}_{\mathrm{i}}$ conditions cause increased intracellular nicotinamide riboside $(\mathrm{NmR})$ levels, which are derived through the catalysis of nicotinamid nucleotids (NMR) by the alkaline phosphatase Pho8, leading to a release of phosphate. We found that the transcript of $U R H 1$, a key enzyme in the NmR-derived $\mathrm{NAD}^{+}$biosynthesis, is increased with decreasing $P_{i}$ supply. Taken together with the increased flux through the NADrequiring glycerol biosynthesis, these outcomes underline the cross-talk between phosphate signaling and $\mathrm{NAD}^{+}$metabolism. Also, the conversion of glycerol-3-P to glycerol leads to a gain of free phosphate and can hence be considered as a possible reason for the up-regulation of this pathway. Still, a clear impact of reduced phosphate on the glycolytic flux remains to be investigated on a level that was beyond the scope of our study. The determination of activities of the corresponding glycolytic enzymes and the determination of their $\mathrm{K}_{\mathrm{s}}$ values with respect to different phosphate levels could possibly increase the fundamental understanding with respect to the inter-dependency of glycolytic flux and phosphate supply.

The SPA approach identified gene clusters with both decreased (cA1 and cA2) and increased (cB1 and cB2) expression pattern under reduced phosphate supply for the enriched category of protein folding, modification and transport. This category was further divided in distinct sub-groups for biological processes which are related to general protein maturation, based on their GO classifications. Four significantly enriched gene sets, i.e. sub-categories that include genes with distinct roles within the protein processing pathway, were identified. We found that genes involved in ubiquitin-dependent protein catabolism and in transport from ER to Golgi were down-regulated under reduced phosphate supply, whereas genes involved in cell wall organization and biosynthesis and in Golgi vesicle-mediated transport were up-regulated. These observations suggest that the later secretory processing capacity of the cells (postGolgi) was enhanced while the retention-and possibly the quality control-of proteins in the ER was reduced when cells were cultures under reduced phosphate concentrations.

It was also found that both the IAP expression under the control of the TPI1 promoter and the TPI1 transcript levels increased with decreasing phosphate 
supply. To our knowledge, the transcriptional up-regulation of TPI1 as a consequence of reduced phosphate supply has not been reported before. We would like to stress the possibility that the increased IAP transcript levels could also be derived from an increased amplification level of the expression cassette $(2 \mu$ plasmid $)$ harboring the IAP gene, suspecting an increased gene dosage of IAP to cause higher transcript levels. Yet, due to the increase of the transcript level of the genomic TPI1 and its similar trend to the IAP transcript, we consider TPI1 to be transcriptionally regulated by the phosphate supply. Finally, our DEA approach showed a moderate up-regulation of the transcription factor GCR1 (1.7 fold), which is known to regulate the high-level expression of TPI1 [32]. Although transcription factors are generally believed to be regulated posttranscriptionally, the increased transcription of GCR1 is in accordance to our finding regarding the TPI1 expression dependency on phosphate availability, and thus can be considered as a possible reason for the upregulation of TPI1. Still, the increased transcription of IAP cannot be considered as the sole reason for the increased secretory production of IAP. The initial decrease of $P_{i}$ from $[33 \mathrm{mM}]$ to $[14.7 \mathrm{mM}]$ did not significantly affect the transcript levels of IAP (increase of $6.9 \%$ with a SD of $3.6 \%$ ), yet the yield of secreted IAP increased $22.6 \%$, suggesting that the global increase of the secretory flux, i.e. the increased secretion of diverse phosphatases and high affinity phosphate transporters, did also benefit the secretory production of IAP. In follow-up studies, and for separately addressing the impact of reduced phosphate supply on both the transcription and the secretion of a heterologous protein, the glycolytic TPI1 promoter should be replaced with a non-glycolytic promoter, e.g. TEF1, as by de-coupling the two identified conjectures for improved IAP secretion found in this study, more explicit conclusions would be promoted

As TPI1 is one of the most commonly used glycolytic promoters for recombinant expression of diverse heterologous proteins in yeast, our data suggests that a special care needs to be taken with the design of the growth media with respect to phosphate supply. For most commonly used media for laboratory scale studies, e.g. derivatives of [33], supply a high amount of phosphate to ensure optimal conditions for biomass formation. The supplied $\mathrm{P} / \mathrm{C}$ ratio of 0.4 ( $\mathrm{mM}$ phosphate per $\mathrm{mM}$ glucose) is 8 fold higher than the starting $\mathrm{P} / \mathrm{C}$ ratio we used in this study (0.05). In addition, we report that a two fold gain of cell specific productivity and $25 \%$ increase of volumetric productivity can be achieved by further decreasing the phosphate supply to at least half of the initial concentration.

\section{Conclusions}

In the present study, we looked into the physiological impacts of phosphate shortage in an industrial API production process. We identified a positive effect of reduced phosphate supply on the secretory production of human insulin in S. cerevisiae. The cellular response towards reduced phosphate levels in the medium was pictured in the up-regulation of multiple phosphatases and permeases that are channeled towards the extracellular space, thus leading to an increased activity of the protein trafficking pathway. By following the successive response of reduced phosphate levels on the physiological state of cells, we identified a range of interest for improved IAP productivity, covering low but not critical $P_{i}$ levels. The consecutive methodology we applied for studying the regulatory shifts from cells growing under carbon limitation towards phosphate limitation resulted in more profound insights into the adaptive response of the cells to their nutrient availability. By combining information obtained through the analysis of differentially expressed genes among low and high phosphate levels, with the identification of significant gene expression patterns which followed major phenotypic observations, e.g. IAP productivity, we enlarged the picture of cellular events during growth on reduced phosphate levels.

Our work underlines the inter-connection among the signaling of phosphate scarcity, the re-distribution of glycolytic flux towards glycerol and ethanol production, the phosphatidylinositol biosynthesis, the NAD biosynthesis, and the polyphosphate metabolism. Moreover, we emphasize the importance of optimized media formulation with respect to a reduced $\mathrm{P} / \mathrm{C}$ ratio, aiming at improved heterologous protein production. We conclude that a dietary supply of phosphate can potentially enhance the secretory production of a heterologous protein. Under reduced phosphate levels, the usage of the glycolytic TPI1 promoter further increased the recombinant transcript levels of the IAP gene, advancing the overall productivity of the target protein.

\section{Methods}

\section{Expression backbone}

The haploid S. cerevisiae strain CEN.PK113-11C (MATa, ura3-52 his3-D1, MAL2-8c SUC2) was transformed with the URA3d based expression cassette pU17 via LiAc method, according to [34]. The 2 micron vector $\mathrm{pU} 17$ is a HIS3 plasmid derived from [35], with an expression cassette containing the TPI1 promoter and the insulin analogue precursor (IAP) gene that encodes an insulin Asp ${ }^{\text {B28 }}$ molecule where the A- and B-chain are connected by a EWK C-peptide [36]. The secretory expression of the insulin precursors was performed with the aid of the mating 
type factor alpha leader in the configuration: $\alpha$-factor leader-KR-spacer-insulin precursor, leading to an optimized processing of the fusion protein by the native Kex2 endoprotease, as described by [37]. The expression cassette also contains the $U R A 3$ open reading frame plus 17 base pairs of the endogenous URA3 promoter. Both HIS3 and URA3 were used as auxotrophic selection markers. The URA3d based plasmids provide an increased pool of the recombinant gene (IAP) as the defective URA3 gene led to amplified plasmid copy numbers (Kazemi Seresht et al., in preparation).

\section{High cell density cultivation}

The batch phase was followed by a carbon-limited fedbatch phase with an open loop controlled specific growth rate of $\mu_{\text {set }}=0.1 \mathrm{~h}^{-1}$. During this phase, $55 \mathrm{gL}^{-1}$ glucose was added to the process (feed concentration $500 \mathrm{gL}^{-1}$ ). The fed batch phase was automatically initiated after glucose depletion during the batch phase, monitored and controlled with the decrease of the carbon dioxide signal in the off-gas measurement. The chemostat phase was automatically initiated after the fed batch phase. The culture volume was controlled via a gravimetric feed control, ensuring a fixed dilution rate of $D=0.1 \mathrm{~h}^{-1}$. The respiratory quotient $(\mathrm{RQ})$ and the at-line analysis of ethanol in the exhaust gas were monitored, confirming a fully respiratory growth of the cells during the fed batch and chemostat phases, i.e. the chosen dilution rate was lower than the critical dilution rate and no ethanol formation was detected. The $\mathrm{pH}$ was controlled at 5.9 by addition of $\mathrm{NH}_{4} \mathrm{OH}(10 \%)$, which provided a non-limiting nitrogen source throughout the whole process. The temperature was controlled at $28^{\circ} \mathrm{C}$, and the dissolved oxygen tension (DOT) was kept above $40 \%$ of saturation to avoid oxygen limitation. Cultivations were performed in the Sartorius Stedim Biotech BIOSTAT Qplus ${ }^{\circledR}$ (0.4 L scale).

\section{Media formulation}

The defined growth medium for plates was $6.7 \mathrm{gl}^{-1}$ yeast nitrogen base without amino acids, but with ammonium sulphate, $2 \%$ glucose, $2 \%$ agar and the relevant CSM drop-out amino acid mixture (from Qbiogene). A defined minimal medium (DMM) was used in all experiments. Its basal composition for pre-cultures $(5 \mathrm{~mL}$ scale in $50 \mathrm{~mL}$ falcon tubes) and shake flasks $(100 \mathrm{~mL}$ scale in $500 \mathrm{~mL}$ shake flasks with two baffles) was: 10.5 $\mathrm{gL}^{-1}$ Potassium hydrogen phthalate (KHP), $5 \mathrm{gL}^{-1}\left(\mathrm{NH}_{4}\right)$ ${ }_{2} \mathrm{SO}_{4}, 2 \mathrm{gL}^{-1} \mathrm{KH}_{2} \mathrm{PO}_{4}, 0.5 \mathrm{gL}^{-1} \mathrm{MgSO}_{4} \cdot 7 \mathrm{H}_{2} \mathrm{O}, 0.1 \mathrm{gL}^{-1}$ $\mathrm{CaCl}_{2} \cdot 2 \mathrm{H}_{2} \mathrm{O}, 100 \mu \mathrm{LL}^{-1}$ antifoam (Antifoam 204, Sigma-Aldrich), $1 \mathrm{mLL}^{-1}$ trace metals solution, $1 \mathrm{mLL}^{-1}$ vitamin stock solution, and an initial glucose concentration of $20 \mathrm{gL}^{-1}$. The trace metal and vitamin solutions were derived from [33]. For chemostat experiments, a modified DMM was used with the following composition: $3 \mathrm{gL}^{-1} \mathrm{KH}_{2} \mathrm{PO}_{4}, 2 \mathrm{gL}^{-1}\left(\mathrm{NH}_{4}\right)_{2} \mathrm{SO}_{4}, 1.5 \mathrm{gL}^{-1}$ $\mathrm{MgSO}_{4} \cdot 7 \mathrm{H}_{2} \mathrm{O}, 0.2 \mathrm{gL}^{-1} \mathrm{CaCl}_{2} \cdot 2 \mathrm{H}_{2} \mathrm{O}, 0.1 \mathrm{gL}^{-1} \mathrm{NaCl}, 200$ $\mu \mathrm{LL}^{-1}$ antifoam, $10 \mathrm{mLL}^{-1}$ trace metals solution, 10 $\mathrm{mLL}^{-1}$ vitamin stock solution. The initial glucose concentration in the batch was set to $20 \mathrm{gL}^{-1}$, and in the chemostat medium to $75 \mathrm{gL}^{-1}$. Cultivations were carried out under six different phosphate concentrations, using $\mathrm{KH}_{2} \mathrm{PO}_{4}$ as phosphate source (Table 1 ). The resulting alternations in the potassium (K) levels were compensated for by addition of $\mathrm{KCl}$.

\section{Microarray analysis Sampling method}

Samples for RNA isolation were taken during the steady state phase of the cultivations. Three samples were withdrawn within 48 hours and used as biological replicates for each culture. For the sampling, $5 \mathrm{~mL}$ culture broth were rapidly taken into a $50 \mathrm{~mL}$ sterile Falcone tube, prefilled with $25 \mathrm{~mL}$ of crushed ice, in order to decrease to sample temperature to below $4^{\circ} \mathrm{C}$ in a few seconds. Cells were centrifuged ( $4000 \mathrm{rpm}$ at $0^{\circ} \mathrm{C}$ for $2 \mathrm{~min}$.), the supernatant discarded, the pellet was frozen in liquid nitrogen and stored at $-80^{\circ} \mathrm{C}$, and the RNA extraction was performed within a month. Total RNA was extracted using the Ambion RiboPure Yeast Kit (Applied Biosystems, Austin, USA), according to manufacturer's instruction, after thawing the cell pellets on ice. RNA sample integrity was determined with an Agilent 2100 Bioanalyzer and RNA 6000 Nano LabChip kit (Agilent, Santa Clara, CA), ensuring RIN values above 9.0, and total RNA quantity was determined with a NanoDrop 3300 UV-Vis spectrophotometer (Thermo Scientific, Rockford, USA).

\section{Microarray analysis and data acquisition}

Using the 3'IVT Expression Kit (One-Cycle cDNA Synthesis) and the GeneChip Hybridization, Wash and Stain Kit, the probe preparation and hybridization to Affymetrix Yeast Genome Y2.0 arrays were performed according to manufacturer's instructions (Affymetrix GeneChip Expression Analysis Technical Manual, P/N 702232, Rev.2). Washing and Staining of arrays were performed using the GeneChip Fluidics Station 450 and

\begin{tabular}{|c|c|c|}
\hline $\begin{array}{c}P_{i} \text { conc. } \\
\text { [culture ID] }\end{array}$ & $\begin{array}{c}\mathrm{KH}_{2} \mathrm{PO}_{4} \text { in } \mathrm{DMM} \\
{\left[\mathrm{gL}^{-1}\right]}\end{array}$ & $\begin{array}{c}K C L \text { in } D M M \\
{\left[g L^{-1}\right]}\end{array}$ \\
\hline $33 \mathrm{mM}$ & 4.5 & - \\
\hline $22 \mathrm{mM}$ & 3.0 & - \\
\hline $14.7 \mathrm{mM}$ & 2.0 & 0.6 \\
\hline $9.6 \mathrm{mM}$ & 1.3 & 1.0 \\
\hline $5.5 \mathrm{mM}$ & 0.75 & 1.3 \\
\hline $2.6 \mathrm{mM}$ & 0.35 & 1.5 \\
\hline
\end{tabular}


scanning with the Affymetrix GeneArray 3000 7G Scanner (Affymetrix, Santa Clara, CA). The Affymetrix GeneChip Command Console Software (AGCC) was used to generate CEL files of the scanned arrays. Data analysis was performed using the statistical open source language R (R Development Core Team, http://www.r-project.org), supplemented with Bioconductor v2.8 (Bioconductor Core Team, http://www.bioconductor. org). Data preprocessing was carried out by using the Robust Multichip Average method, considering the calculated probe affinity derived from position dependent base effects (GC-RMA), including a quantile normalization of probe intensities and a median polishing step for expression measure calculation.

\section{Gene Expression Analysis}

For the Differential Expression Analysis (DEA), the Linear Models for Microarray Data (LIMMA) method was applied, using the limma statistical package. A moderated $t$-test between the two experiment sets of low (9.6 $\left.\mathrm{mM} \mathrm{P}_{\mathrm{i}}\right)$ and high $\left(22 \mathrm{mM} \mathrm{P}_{\mathrm{i}}\right)$ phosphate supplemented cultures was used for pair-wise comparison. Empirical Bayesian statistics were used to moderate the standard errors within each gene and Benjamini-Hochberg's method was applied to adjust for multiple testing. A cut-off value of adjusted $p<0.05$ was chosen for statistical significance. The statistically significant differential gene expression list was further trimmed by considering only genes with |fold change $>2$ as biological significant. Significant gene ontology (GO) process terms of the selected genes were identified using GO Slim Mapper tools (Saccharomyces Genome Database SGD) with a threshold of $p<0.01$.

For the Significant Profile Analysis (SPA), the MicroArray Significant Profiles (maSigPro) method was applied, using the masigpro statistical package. A twostep linear regression model was used to identify genes with a significant expression profile as a response to alternating phosphate supply, considering gene sets of five different cultures growing at $5.5 \mathrm{mM}, 9.6 \mathrm{mM}, 14.7$ $\mathrm{mM}, 22 \mathrm{mM}$, and $33 \mathrm{mM}$ phosphate concentration in the feed reservoir. The step-wise regression was adjusted to polynomial degree of 2, a significance cut-off of $\alpha=$ 0.05 was used, and an R-squared cut-off of 0.7 was chosen to increase the goodness of the fit. The identified significant gene set was clustered in 10 subsets using a hierarchical clustering method. A similar GO enrichment analysis as for the DEA approach was applied to the identified gene subsets

\section{Analytical methods \\ Extracellular metabolites}

The extra-cellular metabolites glucose, glycerol, acetate, and ethanol were analyzed on a reverse phase HPLC (Agilent 1200), separated on a Rezex ROA-organic acid
$\mathrm{H}^{+}(8 \%) 7.8 \times 300 \mathrm{~mm}$ column (Phenomenex), operating at $45^{\circ} \mathrm{C}$ and at a flow rate of $0.5 \mathrm{mLmin}^{-1}$, using a 5 $\mathrm{mM} \mathrm{H}_{2} \mathrm{SO}_{4}$ solution as running buffer. Detection was done using a refractive index detector.

\section{Human insulin}

Insulin was separated on a reverse phase HPLC (Agilent 1200) on a C4 Jupiter $4.6 \times 250 \mathrm{~mm}(5 \mu \mathrm{m})$ column (Phenomenex), operating at $42^{\circ} \mathrm{C}$ and at a flow rate of 1 $\mathrm{mLmin}^{-1}$. Buffer A was composed of 0.1\% TFA in milliQ water, and buffer $B$ was composed of $0.07 \%$ TFA in acetonitrile, with an elution gradient of $20-80 \%$ B in 20 minutes, $100 \%$ B in 5 minutes, $100-20 \%$ B in 0.1 minutes. The UV-detection was performed at $214 \mathrm{~nm}$, and the concentration was determined using Human Insulin as external standard.

\section{$R T-q P C R$}

Total RNA was extracted using the Ambion RiboPure Yeast Kit (Applied Biosystems, Austin, USA), according to manufacturer's instructions. The RNA extracts were treated with DNAse (TURBO DNAse, Ambion), and the RNA concentration was measured with a Spectrophotometer (Nanodrop $3300^{\circledR}$, Thermo Scientific). For cDNA synthesis, the High Capacity cDNA Reverse Transcription Kit (Applied Biosystems) was used. Quantification of the cDNA levels of the insulin gene (IAP), ACT1 and TPI1 was performed by quantitative PCR using a Stratagene MX3005 ${ }^{\circledR}$ instrument. $A C T 1$ was used as reference gene, with the primer set 5'-GCCTTCTACGTTTCCATCCA-3' and 5'-GGCCAAATCGATTCTCAAAA-3'. Transcript levels were determined for the IAP gene, using the primer set 5'-GAAGCTGAAGCTCCAAAGTTCG-3' and 5'-CGGGCTGCGTCTAGTTACAGTAG-3', and for TPI1, using the primer set 5'TCCCAGAAAATGTCGAAGTTG-3' and 5'GGCTTCTTAACCAAAGAGACAGA-3'. Standard curves were generated pooled cDNA from all samples, and efficiencies close to $100 \%$ were achieved ( $\mathrm{E} \geq 95 \%$ ). Potential primer dimerization effects were excluded via melting curve analysis.

\section{Calculations of yields and productivities}

All yield and productivity calculations are based on averaged concentrations of the corresponding compound, derived from samples that were taken during the steady state phase of cultivations. The biomass yield is represented as $\mathrm{y}_{\mathrm{X} / \mathrm{S}}$ and based on the mass of consumed glucose $(\mathrm{g} / \mathrm{g})$, whereas the yield of the metabolites ethanol and glycerol are represented as $\mathrm{Y}_{\mathrm{E} / \mathrm{S}}$ and $\mathrm{Y}_{\mathrm{G} / \mathrm{S}}$ and based on the molar mass of consumed glucose ( $\mathrm{mmol} /$ $\mathrm{mol})$, respectively. The insulin production yield $\mathrm{y}_{\mathrm{IAP} / \mathrm{X}}$ is based on the cell dry weight $(\mathrm{mg} / \mathrm{g})$. The specific insulin productivity $\mathrm{q}_{\mathrm{IAP} / \mathrm{X}}$ is defined as the product of the dilution rate $(\mathrm{D})$ and insulin production yield $\left(\mathrm{y}_{\mathrm{IAP} / \mathrm{X}}\right)$ during the steady state phase of chemostat cultivations. 


\section{Additional material}

Additional file 1: Sum-up of the GO Slim enrichment analysis. A detailed illustration of the GO Slim enriched categories of clusters CA (page 1), CA2 (page 2), CB1 (page 3), and CB2 (page 4) is shown as presented in Figure 3.

\section{Acknowledgements}

This work was financially supported by Novo Nordisk A/S and the Danish Ministry of Science Technology and Innovation (VTU).

\section{Author details}

'Protein Expression, Novo Nordisk A/S, Novo Nordisk Park 1, 2760-Måløv, Denmark. ${ }^{2}$ Industrial Biotechnology, Department of Chemical and Biological Engineering, Chalmers University of Technology, 41296-Gothenburg, Sweden.

\section{Authors' contributions}

LO and EAP supervised the research and contributed to the revision of the manuscript. AKS designed and performed the experiments, carried out the data analysis and drafted the manuscript. All authors have read and approved the manuscript.

\section{Competing interests}

The authors declare that they have no competing interests.

Received: 13 September 2011 Accepted: 7 December 2011 Published: 7 December 2011

\section{References}

1. Porro D, Gasser B, Fossati T, Maurer M, Branduardi P, Sauer M, et al: Production of recombinant proteins and metabolites in yeasts: when are these systems better than bacterial production systems? Applied Microbiology and Biotechnology 2011, 89:939-48.

2. Walsh G: Therapeutic insulins and their large-scale manufacture. Applied Microbiology and Biotechnology 2005, 67:151-9.

3. Sauer M, Porro D, Mattanovich D, Branduardi P: Microbial production of organic acids: expanding the markets. Trends in Biotechnology 2008, 26:100-8.

4. Jarboe LR, Zhang $X$, Wang $X$, Moore JC, Shanmugam KT, Ingram LO Metabolic engineering for production of biorenewable fuels and chemicals: contributions of synthetic biology. Journal of Biomedicine \& Biotechnology 2010, 2010:761042.

5. Otero JM, Nielsen J: Industrial systems biology. Biotechnology and Bioengineering 2010, 105:439-60.

6. Robinson aS, Wittrup KD: Constitutive overexpression of secreted heterologous proteins decreases extractable BiP and protein disulfide isomerase levels in Saccharomyces cerevisiae. Biotechnology Progress 1995, 11:171-7.

7. Kjeldsen T: Yeast secretory expression of insulin precursors. Applied Microbiology and Biotechnology 2000, 54:277-86.

8. Graf A, Dragosits M, Gasser B: Yeast systems biotechnology for the production of heterologous proteins. FEMS Yeast 2009, 9:335-348.

9. Boer VM, Crutchfield CA, Bradley PH, Botstein D, Rabinowitz JD: Growthlimiting intracellular metabolites in yeast growing under diverse nutrient limitations. Molecular Biology of the Cell 2010, 21:198-211.

10. Kolkman A, Daran-Lapujade P, Fullaondo A, Olsthoorn MMA, Pronk JT, Slijper $M$, et al: Proteome analysis of yeast response to various nutrient limitations. Molecular Systems Biology 2006, 2:2006-0026.

11. Brauer MJ, Huttenhower C, Airoldi EM, Rosenstein R, Matese JC, Gresham D, et al: Coordination of Growth Rate, Cell Cycle, Stress Response, and Metabolic Activity in Yeast. Molecular Biology of the Cell 2008, 19:352-367.

12. Gutteridge A, Pir P, Castrillo Jl, Charles PD, Lilley KS, Oliver SG: Nutrient control of eukaryote cell growth: a systems biology study in yeast. BMC Biology 2010, 8:68.

13. Conesa A, Nueda MJ, Ferrer A, Talón M: maSigPro: a method to identify significantly differential expression profiles in time-course microarray experiments. Bioinformatics (Oxford, England) 2006, 22:1096-102.
14. Smets B, Ghillebert R, De Snijder P, Binda M, Swinnen E, De Virgilio C, et al: Life in the midst of scarcity: adaptations to nutrient availability in Saccharomyces cerevisiae. Current Genetics 2010, 56:1-32.

15. Mouillon J-M, Persson BL: New aspects on phosphate sensing and signalling in Saccharomyces cerevisiae. FEMS Yeast Research 2006, 6:171-6.

16. Ogawa N, DeRisi J, Brown PO: New components of a system for phosphate accumulation and polyphosphate metabolism in Saccharomyces cerevisiae revealed by genomic expression analysis. Molecular Biology of the Cell 2000, 11:4309-21.

17. Lenburg M: Signaling phosphate starvation. Trends in Biochemical Sciences 1996, 21:383-387.

18. Lee Y-S, Huang K, Quiocho FA, O'Shea EK: Molecular basis of cyclin-CDKCKI regulation by reversible binding of an inositol pyrophosphate. Nature Chemical Biology 2008, 4:25-32

19. Kaffman A, Rank NM, O'Neill EM, Huang LS, O'Shea EK: The receptor Msn5 exports the phosphorylated transcription factor Pho4 out of the nucleus. Nature 1998, 396:482-486.

20. Auesukaree C, Tochio H, Shirakawa M, Kaneko Y, Harashima S: Plc1p, Arg82p, and Kcs1p, enzymes involved in inositol pyrophosphate synthesis, are essential for phosphate regulation and polyphosphate accumulation in Saccharomyces cerevisiae. The Journal of Biological Chemistry 2005, 280:25127-33

21. Lee Y-S, Mulugu S, York JD, O'Shea EK: Regulation of a cyclin-CDK-CDK inhibitor complex by inositol pyrophosphates. Science 2007, 316:109-12.

22. Kramer RA, DeChiara TM, Schaber MD, Hilliker S: Regulated expression of a human interferon gene in yeast: control by phosphate concentration or temperature. Proceedings of the National Academy of Sciences of the United States of America 1984, 81:367-70.

23. Blondeau K, Boutur O, HeTene B, Moulin G, Galzy P: Influence of culture conditions on the production of heterologous interleukin 1 beta by Kluyveromyces lactis. Biotechnology Techniques 1993, 7:609-614.

24. Kulaev I, Kulakovskaya T: Polyphosphate and phosphate pump. Annual Review of Microbiology 2000, 54:709-34.

25. Angus R, Lester WW: Turnover of Inositol and Phosphorus Containing Lipids in Saccharomyces cerevisiae; Extracellular Accumulation Derived of Glycerophosphorylinositol from Phosphatidylinositol. Archives of Biochemistry and Biophysics 1972, 151:483-495.

26. Almaguer C, Mantella D, Perez E, Patton-Vogt J: Inositol and phosphate regulate GIT1 transcription and glycerophosphoinositol incorporation in Saccharomyces cerevisiae. Eukaryotic Cell 2003, 2:729.

27. Carroll AS, Bishop AC, DeRisi JL, Shokat KM, O'Shea EK: Chemical inhibition of the Pho85 cyclin-dependent kinase reveals a role in the environmental stress response. Proceedings of the National Academy of Sciences 2001, 98:12578-83.

28. Almaguer C, Cheng W, Nolder C, Patton-Vogt J: Glycerophosphoinositol, a novel phosphate source whose transport is regulated by multiple factors in Saccharomyces cerevisiae. The Journal of Biological Chemistry 2004, 279:31937-42.

29. Pahlman AK, Granath K, Ansell R, Hohmann S, Adler L: The yeast glycerol 3-phosphatases Gpp1p and Gpp2p are required for glycerol biosynthesis and differentially involved in the cellular responses to osmotic, anaerobic, and oxidative stress. The Journal of Biological Chemistry 2001, 276:3555-63.

30. Ansell R, Granath K, Hohmann S, Thevelein JM, Adler L: The two isoenzymes for yeast NAD + -dependent glycerol 3-phosphate dehydrogenase encoded by GPD1 and GPD2 have distinct roles in and redox regulation osmoadaptation. EMBO Journal 1997, 16:2179-2187.

31. LU S-P, Lin S-J: Phosphate responsive signaling pathway is a novel component of NAD+ metabolism in Saccharomyces cerevisiae. The Journal of Biological Chemistry 2011, 286:14271-14281.

32. Scott EW, Baker HV: Concerted action of the transcriptional activators REB1, RAP1, and GCR1 in the high-level expression of the glycolytic gene TPI. Molecular and Cellular Biology 1993, 13:543-50.

33. Verduyn C, Postma E, Scheffers WA, Van Dijken JP: Effect of benzoic acid on metabolic fluxes in yeasts: a continuous-culture study on the regulation of respiration and alcoholic fermentation. Yeast (Chichester, England) 1992, 8:501-17.

34. Gietz RD, Woods RA: Genetic transformation of yeast. Biotechniques 2001 30:816-831.

35. Christianson TW, Sikorski RS, Dante M, Shero JH, Hieter P: Multifunctional yeast high-copy-number shuttle vectors. Gene 1992, 110:119-22. 
36. Kjeldsen T, Ludvigsen S, Diers I, Balschmidt P, Sorensen AR, Kaarsholm NC: Engineering-enhanced protein secretory expression in yeast with application to insulin. The Journal of Biological Chemistry 2002, 277:18245-8

37. Kjeldsen $T$, Brandt J, Andersen AS, Egel-Mitani M, Hach M, Pettersson AF

et al: A removable spacer peptide in an alpha-factor-leader/insulin precursor fusion protein improves processing and concomitant yield of the insulin precursor in Saccharomyces cerevisiae. Gene 1996, 170:107-12.

doi:10.1186/1475-2859-10-104

Cite this article as: Kazemi Seresht et al:: The impact of phosphate

scarcity on pharmaceutical protein production in S. cerevisiae: linking transcriptomic insights to phenotypic responses. Microbial Cell Factories 2011 10:104

Submit your next manuscript to BioMed Central and take full advantage of:

- Convenient online submission

- Thorough peer review

- No space constraints or color figure charges

- Immediate publication on acceptance

- Inclusion in PubMed, CAS, Scopus and Google Scholar

- Research which is freely available for redistribution

Submit your manuscript at www.biomedcentral.com/submit 